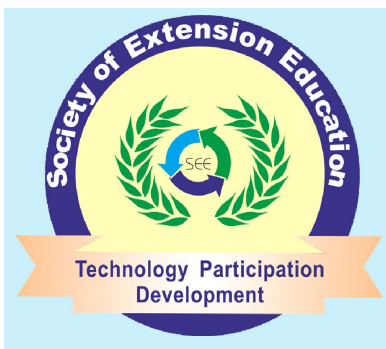

Research Note

\section{Indian Research Journal of Extension Education}

ISSN: 0972-2181 (Print), 0976-1071 (Online)

NAAS Rating : 5.22

Journal homepage: seea.org.in

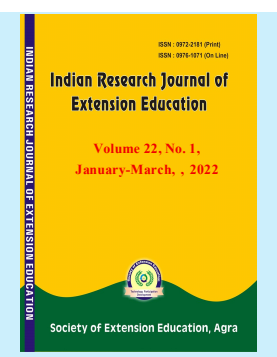

https://doi.org/10.54986/irjee/2022/jan_mar/123-127

\title{
A Measurement Tool for the Assessment of Farmers' Perception about Impact of Changing Climate on Agriculture in India
}

\author{
Rohit Shelar ${ }^{1}$, A. K. Singh ${ }^{2}$ and Saikat Maji ${ }^{3}$ \\ 1.Res. Scholar, 2.Prof., 3.Asstt. Prof., Extension Education, I.A.Sci., BHU, Varanasi (Uttar Pradesh), India \\ Corresponding author e-mail : rohit.shelar10@bhu.ac.in
}

Paper Received on September 11, 2021, Accepted on November 12, 2021 and Published Online on January 01,2022

\begin{abstract}
Changing climate is a serious environmental problem affecting agricultural productivity at global level. It is important to study the perceptions of farmers' towards changing climate and its impact on agriculture as it is one of the strong interpreters of changing farmers' behaviour to mitigate climate change and adopt adequate and appropriate measures to ensure agricultural production. For the construction of the scale to measure the farmers' perception, summating rating method suggested by Likart (1932) was followed. Based on review of literature 79 statements were enlisted initially and 21 statements were finalized for the final construction of the scale. The reliability and validity of the scale was calculated to find out the precision and consistency of the results. This scale will be helpful for interested policy makers, academicians and researchers who willing to study the farmers' perceptions about climate change and its impact on agriculture.
\end{abstract}

Key words : Agriculture; Climate change; Impact, Perception;Scale.

Climate change is a serious global environmental issue that is primarily caused by the building up of Green House Gases (GHG) in the atmosphere. Increased anthropogenic activities such as industrialization, urbanization, deforestation leading to the emission of greenhouse gases like carbon dioxide, methane, and nitrous oxide, due to the burning of fossil fuel, change in land use and many other reasons result in a faster the rate of climate change (USGCRP 2014, Chigbo A.et $a l$, 2016) Changing climate may bring extra hardship for farming activities, often carried out by the poor people through loss of harvests, often their single sources of food and income, and make them the most vulnerable to climate change (Parikh, 2007). In Asia, agricultural crop yield is expected to decline up to 5 to $30 \%$ by $2050 \mathrm{~s}$ due to rising temperatures; and this decline in agricultural yield will lead to food insecurity, which will become the most serious future problem for human beings to deal with (Raghuvanshi et al. 2017). In case of India, studies found that Indian agriculture will be negatively affected by climate change. With an increase in onedegree temperature, a 3-7\% reduction in crop yield is expected. (Aggarwal et al. 2009). Goundappa et al. (2012) conducted an experiment on farmers' perception and awareness of crop insurance and found that, because of less rainfall in the north-eastern part of Karnataka, farmers suffer from drought and dry spell every year. Such a situation is occurring in several states of India which has sometimes compelled the poor farmers to commit suicide due to crop failure. Thus, 
climate change is arising as the biggest threat to agriculture and those dependent on it, not only in India but also for global food security. To tackle this challenge, the first step towards any effective policy formulation and promotion of climate mitigating technology and practices is to develop an in-depth knowledge of how farmers are perceiving climate change, its signs, causes, impact, and future threats. A study conducted by Kumar and Sidana (2018) on Farmers of Punjab province of India, found that positive perception often leads to better adoption of innovations like laser leveller and improved irrigation structures in response to climate variability. Thus, under this study, an effort has been made to design a reliable and valid scale to measure the perception of the farmers about the impact of climate change on agriculture in order to facilitate the successful adaptation of climate-smart technologies in the field of agriculture.

\section{METHODOLOGY}

Ban et al. (2000) define perception as the process by which we receive information or stimuli from our environment and transform it into psychological awareness. It is interesting to see that people infer about a certain situation or phenomenon differently using the same or different sets of information. Knowledge, interest, culture, and many other social processes that shape the behavior of an actor who uses the information and tries to influence that particular situation or phenomenon (Banjade, 2003). The perception was operationally defined as understanding, interpreting, and organizing the meaningful sensations about the environment by the respondents. For the construction of the tool, the summating rating method suggested by Likart (1932), Edwards (1957), and Patil et al. (1996) were followed. The scale was developed by following these steps:

Collection and editing of statements : Collection of the set of items related to climate change and its impact on agriculture was done from available literature on the internet, books, magazines, journals, newspaper articles, etc. and also with consultation with subject expert. In the beginning, 79 statements were enlisted (Table 1) after consulting with the researchers, extension experts, and farmers. Further, the statements were then edited according to the fourteen criteria given by Edward (1957). For the sake of easiness in the application of the scale, the identified statements were grouped in four dimensions such as perception about signs of climate change, its causes, its impact, and future threats.

Relevancy test : To test the relevancy of statements and screening for final selection in scale, all the enlisted statements were subjected to be a careful examination by an expert panel of judges as it may be possible that all the collected statements may not be relevant equally in measuring the perception of farmers' about climate change. For this, all the 79 statements were grouped under four categories and were sent to a panel of judges. The panel included experts and researchers in the field of Extension Education and climate studies. For the critical evaluation of each statement, a set of 79 statements was sent to 90 judges with necessary instructions for its relevancy measurement for the perception of the farmers' about climate change. The judges were requested to give their response on a threepoint continuum viz., Most relevant, relevant, and least relevant with scores 3, 2, and 1, respectively. Out of 90 judges, 39 judges responded in the given period, out of which 6 responses were rejected due to ambiguity. In the end, the score given by 33 judges was considered for the calculation. After for the computation of Relevancy Percentage (RP), Mean Relevancy Weightage (MRW) and Mean Relevancy Score (MRS) of all selected statements following formulae were used:

Relevancy percentage : Relevancy percentage was worked out by summing up the scores of most relevant and relevant categories, which were converted into percentage.

Where $\quad \mathrm{RP}=\frac{\mathrm{FS}}{\text { No. of respondents }} \times 100$

$\mathrm{FS}=$ Frequency score of most relevant and relevant

Relevancy Weightage (R.W.): Relevancy weightage was obtained by the formula.

$$
\mathrm{RW}=\frac{\mathrm{MRR} \times 3+\mathrm{RR} \times 2+\mathrm{LRR} \times 1}{\mathrm{MPS}} \times 100
$$

R.W $=$ Most relevant response $\times 3+$ relevant response $\times 2+$ Least relevant response $\times 1 /$ maximum possible score $(33 \times 3$ =99).

Mean Relevancy Score (M.R.S.) : Mean relevancy score was obtained by the following formula.

$$
\mathrm{MRS}=\frac{\mathrm{MRR} \times 3+\mathrm{RR} \times 2+\mathrm{LRR} \times 1}{\text { No. of Judges }}
$$

M.R.S. $=$ Most relevant response $\times 3+$ relevant response $\times 2$ + Least relevant response $\times 1 /$ Number of judges (33). 
Using these three criteria the statements were screened for their relevancy. Accordingly, statements having relevancy percent greater than 80 , relevancy weightage greater than 0.80 , and mean relevancy score greater or equal to overall mean relevancy score i.e. 2.23 were considered for final selection. With the help of this process, in the first stage, 30 statements were sorted (Table 2) which were further rewritten and modified as per the suggestions given by experts.

Item analysis : For the construction of a valid and reliable scale item analysis is an important step in the Likert technique. It was important to portray the items based on the extent to which they can differ the respondent with high perception than with the low perception about climate change. With this interest, item analysis was done for the statement selected in the first stage. A schedule composed of 30 statements (Table 2) was used for interviewing a sample of 31 respondents from the non-sampling area. The responses for the statements were computed on a similar five-point continuum as it will be during the administration of the finalized scale viz., strongly agree, agree, can't say, disagree, and strongly disagree with scores of 5, 4, 3, 2, and 1 , respectively. Further, the perception score of the respondent was obtained computing the scores of all statements. For item analysis, the respondents were arranged in ascending order based on perception score. Twenty-five percent of the respondents with the highest total scores and $25 \%$ with the lowest total scores were selected. These two groups provided the criterion groups in terms of evaluating the individual statements as suggested by Edwards (1957). Thus, out of 31 respondents to whom the items were administered for the item analysis, 8 farmers with the highest and 8 with lowest scores were used as a criterion group to evaluate the individual item. The critical ratio was calculated by $t$-test. The ' $t$ ' value is a measure of the extent to which a given statement differentiates the high group from the low group. The ' $t$ ' value was calculated by using the formula suggested by Edwards (1957).

Where,

$$
\mathrm{t}=\frac{\mathrm{X}_{\mathrm{H}}-\mathrm{X}_{\mathrm{L}}}{\sqrt{\frac{\mathrm{S}_{\mathrm{H}}^{2}}{\mathrm{n}_{\mathrm{H}}}+\frac{\mathrm{S}_{\mathrm{L}}^{2}}{\mathrm{n}_{\mathrm{L}}}}}
$$

$\mathrm{X}_{\mathrm{H}}=$ the mean score on a given statement for the high group $X_{L}=$ the mean score on the same statement for the low group $\mathrm{S}^{2}{ }_{\mathrm{H}}=$ the variance of the distribution of responses of high group to the statement
$\mathrm{S}^{2}{ }_{\mathrm{L}}=$ the variance of the distribution of responses of low group to the statement

$\mathrm{n}_{\mathrm{H}}=$ number of subjects in the high group;

$\mathrm{n}_{\mathrm{L}}=$ number of subjects in the low group

Selection of Statements for final scale: After knowing " $\mathrm{t}$ " value for all the items, 21 statements with highest " $t$ " value equal to or greater than 1.75 were selected. The thumb rule of rejecting the items with ' $t$ ' value less than 1.75 was followed (Bird, 1940). As per the thumb rule, selection of items (i.e. statements) to be retained in the scale was based on the highest discriminating values, besides eliminating those with poor discriminating ability and questionable validity. Thus, those 21 statements which is simple and presenting a new idea and also statement having ' $t$ ' value more than 1.75 , were finalized in the scale.

Standardization of the scale: The validity and reliability were assured for standardization of the scale. The validity was confirmed by content validity and criterion validity.

Validity: The content validity of the scale was tested. The content validity is the representativeness or sampling adequacy of the content, the substance, the matter and the topics of a measuring instrument. As the content of the scale thoroughly covered the universe of climate change perception in agriculture through literature review and experts' opinion, it was assumed that present scale satisfies the content validity. Thus, scale value difference for all the statements has a high discriminating value and it seems reasonable to accept the scale as a valid measurement.

Reliability: The split-half method for testing reliability was used. The scale was split into two halves on the basis of odd and even number of items and administered to 31 farmers. Thus, two sets of scores were obtained. The Pearson's product moment correlation coefficient was calculated. The value of correlation coefficient was 0.91 and this was further corrected by using Spearman's Brown formula and obtained the reliability coefficient of the whole set. The r-value for scale was 0.93 , which was significant at $0.01 \mathrm{p}$ indicating high reliability of the instrument.

\section{RESULTS AND DISCUSSION}

Table 1 indicated that, 30 statements were having relevancy percent greater than 80 , relevancy weightage greater than 0.80 , and mean relevancy score greater or 
Table 2. Selected statements for final scale

\begin{tabular}{|c|c|}
\hline Statements & ' $t$ ' Value \\
\hline \multicolumn{2}{|l|}{ a. Perception about signs of climate change } \\
\hline *Weather conditions are getting worst day by day. & 7.171805 \\
\hline *The atmospheric temperature has increased. & 2.688086 \\
\hline *Onset and offset of monsoon have delayed. & 3.34664 \\
\hline *The unpredictability of monsoon has increased. & 5.15037 \\
\hline *Uneven distribution of rainfall during monsoon has increased. & 3.05505 \\
\hline *Summer has become warmer. & 6.768913 \\
\hline *The frequency of natural disasters increased. & 4.91935 \\
\hline *Climatic conditions have become more favourable for disease \& pest outbreaks. & 3.900947 \\
\hline \multicolumn{2}{|l|}{ b. Perception about Climate change and its causes } \\
\hline Intensified industrialization is responsible for changing the climate. & 0.966092 \\
\hline Deforestation is the prime reason for changing climate. & 0.509175 \\
\hline Loss of biodiversity contributes to changing climate. & 0 \\
\hline The overact of natural resources is responsible for changing the climate. & 0 \\
\hline Environmental pollution is the primary reason for the changing climate. & -1.12815 \\
\hline Gases released primarily by the burning of fossil fuels are responsible for changing climate. & 0 \\
\hline *Unnecessary and excessive use of resources and services are responsible for changing the climate. & 6.768913 \\
\hline *The increasing population is responsible for the changing climate. & 4.248839 \\
\hline \multicolumn{2}{|l|}{ c. Perception about impact of climate change on agriculture } \\
\hline *Because of the changing climate cropping pattern has changed. & 4.291975 \\
\hline *The changing climate has affected crop maturity. & 5.462793 \\
\hline *The intensity of damage to agricultural production has increased due to natural disasters. & 2.898275 \\
\hline *Human health is threatened by increased pesticide use due to increased pest pressures. & 4.291975 \\
\hline Intensity of damage due to diseases \& pests has increased. & 0.68313 \\
\hline The level of groundwater has decreased. & 0.509175 \\
\hline *The occurrence of drought has increased. & 2.545875 \\
\hline *The changing climate is affecting food security. & 6.06845 \\
\hline \multicolumn{2}{|l|}{ d. Perception about future threats due to climate change } \\
\hline *The frequency of natural disasters may increase in the future. & 3.98862 \\
\hline *Farming practices and technology may change due to climate change. & 6.06845 \\
\hline Cost of cultivation may increase in the future due to adoption of mitigation strategies. & 1.440165 \\
\hline *Grain quality may affect in the future because of the changing climate. & 3 \\
\hline *Resistance in pests may increase in the future. & 7.514431 \\
\hline *Ecological degradation may occur in the future due to climate change. & 6.06845 \\
\hline
\end{tabular}

*Selected statements

equal to overall mean relevancy score. 2.23 were considered for item analysis. Further on the basis of critical ratio computed with the help of t-test, 21 statements having ' $t$ ' value more than 1.75 were selected in final scale. All the statements in the scale have equal weightage and need to respond with a degree of agreeness or disagreeness for measuring perception. Table 1 further described that, all the statements from first dimension i.e. perception about Signs of Climate change were included in the administration of the final scale while, in case of second dimension i.e. perception about Causes of climate change, statement, Unnecessary and excessive use of resources and services are responsible for changing the climate and The increasing population is responsible for the changing climate, were finalized. Third dimension perception about Impact of changing climate on agriculture shows out of the 8 statements, Intensity of damage due to diseases $\&$ pests has increased and the level of groundwater has decreased, statements indicated 0.68 and 0.50 ' $t$ ' value respectively which were rejected from the set. At last in the fourth dimension, perception about Future 
threats of climate change, only one statement i.e. Cost of cultivation may increase in the future due to adoption of mitigation strategies was rejected as the ' $t$ ' value of the statement was 1.44. For the final administration of the scale, the responses had to be recorded on a fivepoint continuum representing strongly agree, agree, can't say, disagree, and strongly disagree with scores of 5, 4, 3,2 , and 1, respectively. The perception score of each respondent can be calculated by adding up the scores obtained by him/her on all the items. The perception score on this scale ranges from a minimum of 21 to a maximum of 105. Based on their scores farmers were divided into three categories viz. high, medium, and low. The higher score indicates that the respondent had more perception about climate change and vice versa.

\section{CONCLUSION}

The perception of the farmers' about changing climate and its adverse impact on agriculture is important for implementing adaptation strategies. Since perception is social and psychological phenomena, the accurate measurement of farmers' perception of climate change and its adverse impact on agriculture will be supportively informing appropriate adaptation strategies. For this, we need reliable and valid measurement tools for correct measurements. This scale will help in the assessment of farmers' perception towards changing climate and how it is impacting on agriculture since the validity and reliability of scale indicated the high precision and consistency of the results. It will be useful for researchers and policymakers and can also be used in other areas for study with suitable modifications.

\section{CONFLICTS OF INTEREST}

The authors declare that they have no conflicts of interest.

\section{REFERENCES}

Aggarwal P.K.; Singh, A.K.; Samra, J.S.; Singh, G.; Gogoi, A.K.; Rao, GGSN; Ramakrishna, YS. (2009). Introduction. In: Aggarwal PK, editor. Global climate change and Indian agriculture. New Delhi: ICAR. p. 1 -5.

Ban, A.W. Van den and Hawkins, H.S. (2000). Agricultural Extension, second edition, Blackwell Science, UK.

Banjade, M.R. (2003). Local perception and use of information for forest user groups: Case studies from Dhankuta district, Nepal. M.Sc. Thesis, Tropical Forestry, Wageningen University, Nepal.

Bird, C. (1940). Social psychology. New York: Appleton Century Crofts;

Chigbo, A. Mgbemene; Chidozie, C. Nnaji and Chekwubechukwu, Nwozor (2016). Industrialization and its Backlash: Focus on climate change and its consequences. Journal of Environmental Science and Technology, 9: 301-316.

Edward, A.L. 1957. Techniques of attitude scale construction. Appleton Century- Crofts, New York.

Goundappa S.B.; Reddy, B.S. and Chandrashekhar SM. (2012). Farmer's perception and awareness about crop insurance in Karnataka. Indian Res J Ext. Edu. II:218-222, Special Issue (Available from:http://www.seea.org.in/special_issue/vol2/ 50.pdf).

Kerlinger Fred N. Foundations of behavioural research. New York: Holt Rinehart and Winston Inc. 1964;379.

Likert, R.A. (1932). A technique for the measurement of attitudes. Archives of Psychology. New York.140.

Patil, S.L.; Swamy, S.B. and Patil, V.G. (1996). Development of scale to measure perception of farmers about usefulness of NAEP. Maharashtra J. of Ext. Edu. XV: 125-131.

Parikh J. (2007). Gender and climate change: framework for analysis, policy and action. India: UNDP.

Raghuvanshi, Rupan and Ansari, M. A. (2016). Farmer's awareness about climate change and adaptation practices: A review. research \& reviews. Journal of Agricultural Science and Technology, 5(3): 41-51.

Kumar, Sunny and Balinder, Kaur Sidana (2018). Farmers' perceptions and adaptation strategies to climate change in Punjab agriculture. Indian Journal of Agricultural Sciences, 88(10): 1573-81.

USGCRP (2014). climate change impacts in the united states: the third national climate assessment. [Melillo, Jerry M., Terese (T.C.) Richmond, and Gary W. Yohe, Eds.] U.S. Global Change Research Program. https://acwi.gov 